\title{
Performance of CO1 and ITS2 nested PCR in molecular identification of ordinary scabies (Sarcoptes scabiei var. hominis)
}

\author{
Gita Dwi Prasasty ${ }^{1,}$, Miftahurrizqiyah ${ }^{2}$, Chairil Anwar $^{1}$, Dwi Handayani ${ }^{1}$, Dalilah ${ }^{1}$, Ahmad Ghiffari ${ }^{3}$, Inda Astri Aryani $^{4}$, \\ Nunuk Dyah Retno Lastuti ${ }^{5}$, Afiat Berbudi ${ }^{6}$ \\ ${ }^{1}$ Department of Parasitology, Faculty of Medicine, Sriwijaya University, Palembang, Indonesia \\ 2 Master Program of Biomedical Science, Faculty of Medicine, Sriwijaya University, Palembang, Indonesia \\ ${ }^{3}$ Department of Parasitology, Faculty of Medicine, Muhammadiyah University, Palembang, Indonesia \\ ${ }^{4}$ Department of Dermatology and Venereology, Dr. Moh. Hoesin Hospital Palembang, Indonesia \\ ${ }^{5}$ Department of Veterinary Parasitology, Faculty of Veterinary Medicine, Airlangga University, Surabaya, Indonesia \\ ${ }^{6}$ Department of Biomedical Sciences, Parasitology Division, Faculty of Medicine, Padjadjaran University, Bandung, Indonesia \\ ${ }^{*}$ Corresponding author: gdprasasty@gmail.com
}

SUBMITTED 3 March 2021 REVISED 5 August 2021 ACCEPTED 26 August 2021

\begin{abstract}
Scabies is a global disease with a high prevalence, causing morbidity and even mortality, especially in poor and developing countries. However, it is often misdiagnosed due to varied and unspecified lesions. The gold standard technique for diagnosis is a microscopic examination, which requires experienced experts in finding mites, mainly in ordinary scabies. CO1 and ITS2 genes have been widely used in molecular identification to detect Sarcoptes scabiei and its variants. This study aimed to determine and compare the sensitivity and specificity of CO1 and ITS2 S. scabiei genes to the microscopic examination of scabies skin scrapings. The skin scrapings of 52 subjects with scabies diagnosed by anamnesis, physical examination, and dermoscopic examination were examined under a microscope and analyzed by nested PCR. The diagnostic test result showed that the sensitivity of nested PCR of both CO1 and ITS2 genes to microscope examination was 100\%. However, the specificity of both CO1 and ITS2 nested PCR was poor (24\% and 0\%). Hence, CO1 and ITS2 nested PCR could be more suitable for screening ordinary scabies in humans than the microscopic examination.
\end{abstract}

KEYWORDS Sensitivity; CO1; ITS2; scabies

\section{Introduction}

Sarcoptes scabiei is an ectoparasite from the order Acarina which causes scabies in humans and mammals. It has a high prevalence in developing countries with tropical climates and high humidity (Liu et al. 2016). Based on the 2015 Global Burden of Disease, Southeast Asia was ranked second with the highest prevalence of scabies after East Asia, and Indonesia was ranked first among 195 countries globally (Karimkhani et al. 2017a). Scabies is transmitted in crowded populations, close intrapersonal skin contact, lack of personal hygiene, low socioeconomic status, and unappropriated sexual behavior (Zayyid et al. 2010).

The most frequent scabies complication due to skin damage is bacterial infections. Streptococcus pyogenes and Staphylococcus aureus can lead to systemic infections such as acute poststreptococcal glomerulonephritis (APSGN), rheumatic fever, and rheumatic heart disease. Consequently, scabies can cause morbidity based on disability-adjusted life year (DALY) and even mortal- ity (Karimkhani et al. 2017a,b). Scabies is also associated with intellectual disability (Liu et al. 2017b). Additionally, scabies has been linked to the production of IL-17, a proinflammatory cytokine, by the immune system. It is a significant immunopathology factor in scabies patients suffering from numerous autoimmune diseases, such as psoriasis and rheumatoid arthritis (Karimkhani et al. 2017a; Liu et al. 2017a).

The accuracy of scabies diagnosis is vital due to the high prevalence and magnitude of the impact of scabies. To date, the diagnosis is based on the presence of two of four cardinal signs as follows: nocturnal pruritus, living in crowded housing, typical lesions and predilections, and microscopic positive (found mites, eggs, or scibala). However, most patients present various and unspecified lesions that often cause misdiagnosis up to 65\% (Hong et al. 2010; Sule and Dankyau 2015). Furthermore, the difficulty of finding parasites during microscopic examination is due to fewer parasites, especially in ordinary scabies.

Polymerase Chain Reaction (PCR) can identify parasites from particular components of mites, eggs, or fe- 
ces left in skin lesions; a microscope cannot observe that. The result of this diagnostic tool can find genetic diversity; even differences between varieties are limited. Mitochondrial haplotypes have been used to demonstrate that the genetic diversity of individual infestations is typically low, from just one to three distinct haplotypes per infestation (Mofiz et al. 2016). The cytochrome c oxidase sub unit 1 (CO1), a gene in mitochondria of each organism's cell, will be amplified in large copy numbers and detected during PCR (Hahm et al. 2018). In addition, the CO1 gene is a potential marker since it can be distinguished from other human ectoparasite mites even with other variants of $S$. scabiei as a large amount of sequencing data exists (Park et al. 2012). The ITS2 gene, located in the mite ribosome, is sensitive to detect $S$. scabiei DNA even after treatment. In addition, this gene can detect genetic variations of species that are related taxonomically (Fukuyama et al. 2010). The study aimed to verify the oriented-nested PCR of CO1 and ITS2 as a tool and screening marker of ordinary scabies.

\section{Materials and Methods}

\subsection{Ethical statement}

This study was approved by the ethical review board of the Faculty of Medicine, Sriwijaya University, Indonesia, in September 2018 (certificate number of 244/kepkrsmhfkunsri/2018). Written consent was obtained from each patient after informing the summary of the study.

\subsection{Subjects of the study}

This study used a diagnostic test design to assess the sensitivity of the CO1 and ITS2 compared to the microscopic examination of scabies skin scrapings. The study was conducted from October 2018 to April 2019. Subjects in this study were all students who lived in boarding schools, fulfilled diagnostic criteria of scabies (cardinal signs), and

TABLE 1 Primers of $\mathrm{CO} 1$ and ITS2 of S. scabiei.

\begin{tabular}{|c|c|c|c|c|}
\hline Gene & Round of PCR & Primers & TM & Ref. \\
\hline \multirow{4}{*}{$\mathrm{CO} 1$} & 1st & $\begin{array}{l}\mathrm{F}: \text { TTTTGATTTTTYYGGW- } \\
\text { CAC }\end{array}$ & & \multirow{8}{*}{ [11] } \\
\hline & & $\begin{array}{l}\mathrm{R}: \text { TAAAGATGARATAG- } \\
\text { TATTTCAAGTT }\end{array}$ & $45^{\circ} \mathrm{C}$ & \\
\hline & 2nd & $\begin{array}{l}\mathrm{F}: \text { TTAGGTTTTATTG- } \\
\text { TATGAGC }\end{array}$ & & \\
\hline & & $\begin{array}{l}\text { R: } \\
\text { GCAAAAACAGCACCTA }\end{array}$ & & \\
\hline \multirow{4}{*}{ ITS2 } & $1 \mathrm{st}$ & $\begin{array}{l}\text { F : AGTATCCGATG- } \\
\text { GCTTCGTTTGTCT }\end{array}$ & \multirow{4}{*}{$56,9^{\circ} \mathrm{C}$} & \\
\hline & & $\begin{array}{l}\text { R : AATCCCGTTTG- } \\
\text { GTTTCTTTTCCTC }\end{array}$ & & \\
\hline & \multirow[t]{2}{*}{ 2nd } & $\begin{array}{l}\text { F : GATGGAAAGGT- } \\
\text { GTCGTCAGATTAATC }\end{array}$ & & \\
\hline & & $\begin{array}{l}\text { R : GATCTGAGGTCGA- } \\
\text { GAAATGACATT }\end{array}$ & & \\
\hline
\end{tabular}

provided informed consent. Consecutive sampling was conducted with a minimum of 47 students. Students positive for scabies by the presence of key symptoms were examined with a dermoscopy by a dermatologist to determine the location of mites. Only patients with two positive cardinal signs and dermoscopy of scabies were included in this study.

Skin scrapings and microscopic examinations were performed directly on-site at the subjects' residencies. The nested PCR analysis was conducted at the Biomolecular Laboratory of Medical Faculty, Sriwijaya University, Indonesia.

\subsection{Sample collection}

Subjects with positive cardinal signs and dermoscopic examination were scrapped by scalpel no.15 and examined under a microscope with a magnitude of $100 \times$. All samples were saved in an Eppendorf tube with alcohol absolute for storage.

\subsection{DNA extraction and PCR amplification}

According to the manufacturer's protocol, the DNA was extracted from the skin scrapings with the DNeasy Kit (Qiagen, Hilden, Germany). The nested PCR analysis was performed using an automatic thermocycler (Biorad) and Go Taq Green Hot Star (Promega, Madison, USA). The primers used are shown in Table 1 . We used wobble primers for the first round of CO1 amplification. New primers of second-round nested PCR were designed to improve the sensitivity of the ITS2 gene.

PCR amplification was performed with 40 cycles of denaturation step at $95{ }^{\circ} \mathrm{C}$ for $5 \mathrm{~s}$, annealing temperature at $45^{\circ} \mathrm{C}$ (CO1) and $56.9^{\circ} \mathrm{C}$ (ITS2) for $5 \mathrm{~s}, 72^{\circ} \mathrm{C}$ for 20 $\mathrm{s}$, and final extension $72{ }^{\circ} \mathrm{C}$ for $1 \mathrm{~min}$. Electrophoresis of the amplicon was carried out in Tris Borate EDTA (TBE) agarose gel $2 \%$ and ethidium bromide stain. The marker of visualization was DNA ladder $100 \mathrm{bp}$. It was confirmed to be positive when an amplicon of 317 bp for CO1 and 417 bp and 272 bp for the first and second round ITS2, respectively. Three samples of each CO1 and ITS2 with clear target bands were then used for sequencing analysis. The sequencing was carried out at PT. Genetika Science and the Geneious program analyzed the result (Kearse et al. 2012).

\subsection{Analysis}

The nested PCR CO1 and ITS2 genes were analyzed using a $2 \times 2$ table for diagnostic test and Epicalc Statistical Software (free to download at https://download.informer.co m/win-1192394082-7270988d-6e716f11/ec2v102.exe) to obtain sensitivity, specificity, positive predictive value, negative predictive value, and accuracy. 


\section{Results and Discussion}

\subsection{Result}

In total, samples from 52 students were included in this study. The total sample was 53, but we excluded one sample, which showed confusing results of the second DNA extraction for amplification (no.16). The CO1 was not detected in the electrophoresis reading result, while ITS2 still did. The socio-demographic characteristics are presented in Table 2 and the distribution of subjects based on symptoms and the dermoscopic examination are presented in Table 3. The microscopic observation of S. scabiei mites and eggs are presented in Figure 1 and Figure 2. The positive results of a diagnostic test were compared

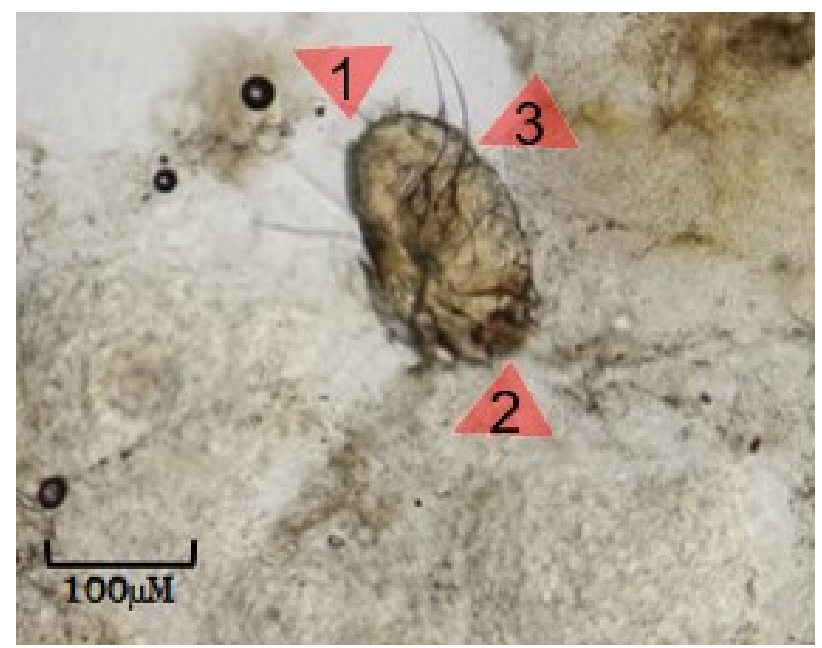

FIGURE 1 Sarcoptes scabiei mite at 100x magnification. The anal opening (1) is facing upward and the capitulum (2) is pointing downward with four legs (3) clearly visible on the left side (lateral view).

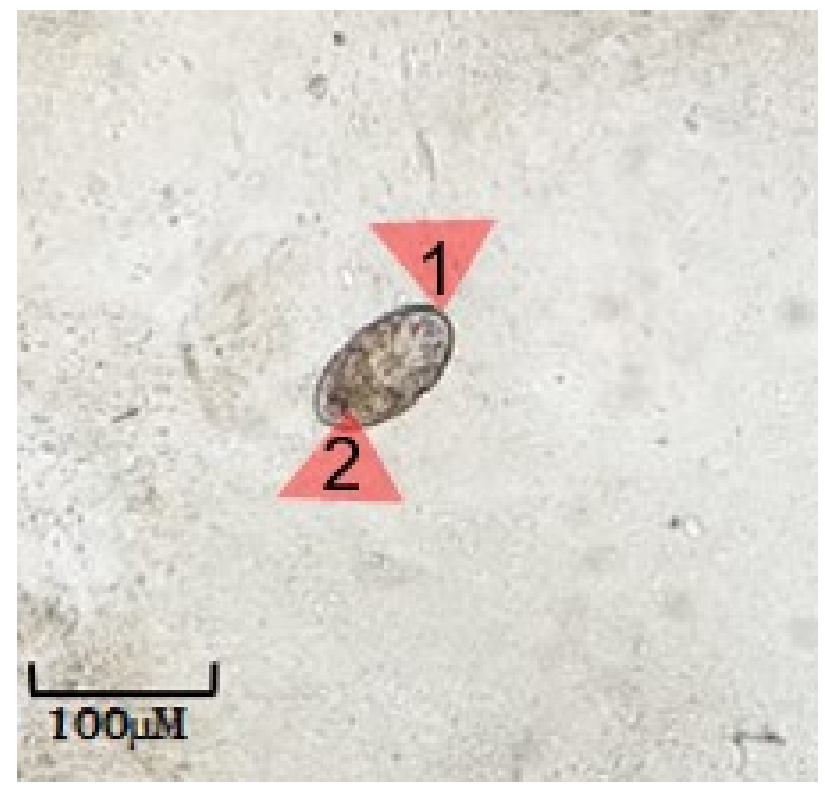

FIGURE 2 Sarcoptes scabiei egg with the larva inside observed under the microscope observation (100x magnification). The egg shell (1) contains a developing larva (2). to the PCR test result and a microscopic examination to assess the clinical value of the nested PCR of the CO1 and ITS2 genes, as shown in Tables 4 and 5, respectively.

All samples identified as positive by microscopic examination also showed positive results by the nested PCR of CO1 and ITS2. These findings suggested that both genes produce $100 \%$ sensitivity. However, all samples identified as negative results by microscopic examination (34 samples) were identified as positive by nested PCR of CO1 gene (76.4\%) and ITS2 (100\%). These results mean that nested PCR of both genes produced poor specificity (Table 4 and 5). Electrophoresis reading results of CO1 and ITS2 genes are shown in Figure 3 and Figure 4.

\subsection{Discussion}

Risk factors of scabies transmission are environmental factors and personal hygiene. Most of the subjects included in this study were female students (73\%). The humid and more closed conditions of the female dormitory may have contributed to scabies related to the lighting conditions, ventilation, humidity, and density of residents. The humid environment is directly proportional to the incidence of scabies (Liu et al. 2016). Mites and the eggs that can survive and are still infective outside the host are the environment's critical transmission (Hay et al. 2012; Arlian and Morgan 2017). Timely treatment and control at an early stage can prevent significant transmission, especially in potent areas like hospitals, jails and boarding schools, and in tropical and developing countries with a high prevalence of scabies and limited health care facilities (Park et al. 2012; Wong et al. 2015). A hospital outbreak that affected more than fifty patients and the staff was successfully cured after the community consisted of more than one thousand patients and caregivers in 3 months. It showed us that late diagnosis or screening of high prevalence scabies had a significant socioeconomic burden for patients and hospitals (Meyer et al. 2011). Furthermore, most of the subjects were new residents, accounting that $77 \%$ of suf-

TABLE 2 Sociodemographic characteristics of subjects $(n=52)$.

\begin{tabular}{lll}
\hline Parameter & Freq & $\%$ \\
\hline Sex & 14 & 27 \\
Male & 38 & 73 \\
Female & & \\
\hline Residence time at boarding school & 28 & 54 \\
$<1$ year & 20 & 38.4 \\
$1-2$ year & 2 & 3.8 \\
$>2-3$ year & 1 & 1.9 \\
$>3-4$ year & 0 & 0 \\
$>4-5$ year & 1 & 1.9 \\
$>5$ year & 12 & 23 \\
\hline History of suffering the same disease & & 77 \\
$\geq 1$ & 40 & \\
0 & 12 & \\
\hline
\end{tabular}




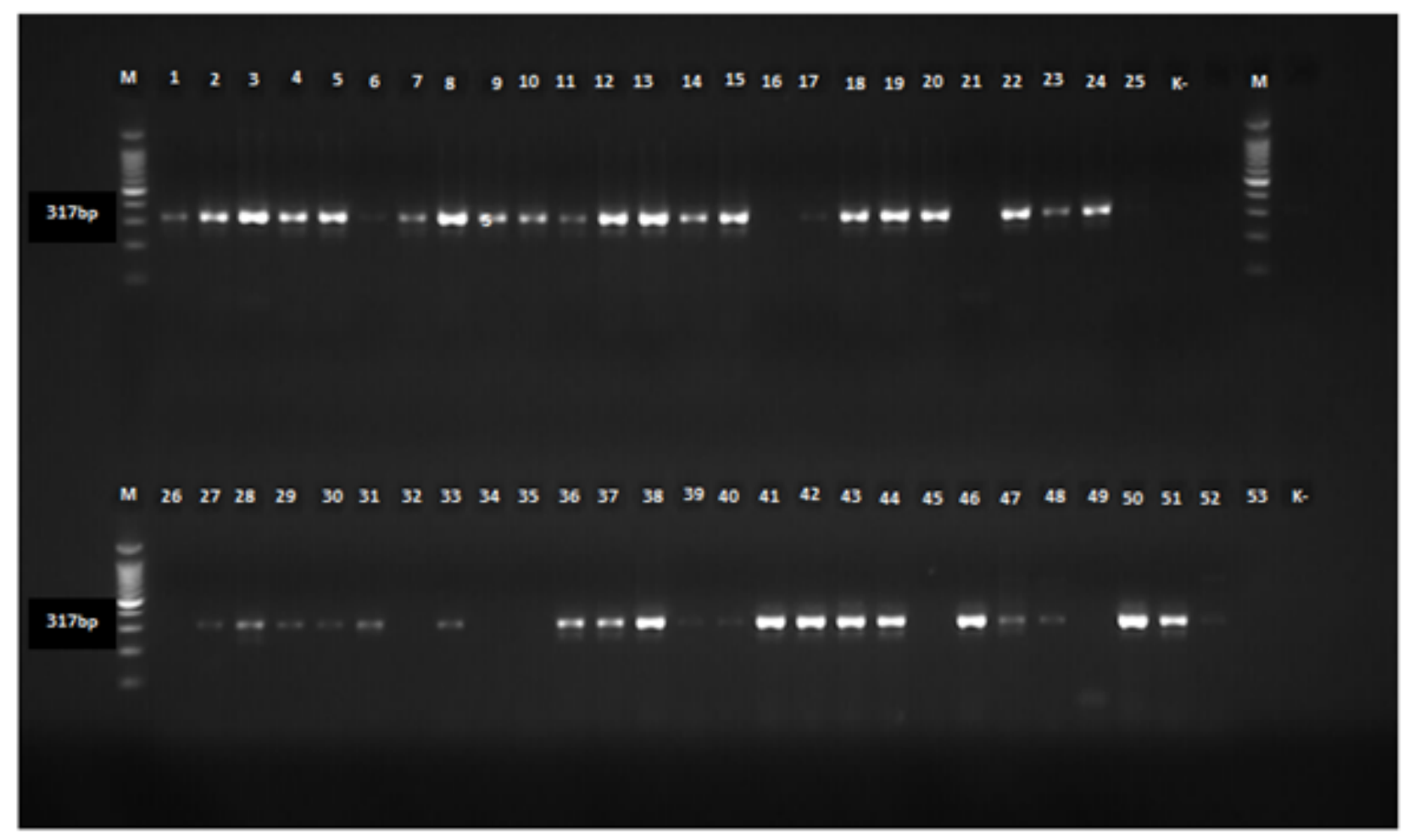

FIGURE 3 Electrophoresis result of nested PCR products of CO1 Sarcoptes scabiei gene. M: 100 bp marker, K- : negative control, 1 - 15, 17 - 20, 22 - 25, 27 - 31, 33, 36 - 44, 46 - 48, 50 - 52 : positive-PCR samples (44 samples); 21, 26, 32,34, 35, 45, 49, 53 : negative-PCR samples (8 samples). $317 \mathrm{bp}$ was the positive band of $\mathrm{CO} 1$ gene.

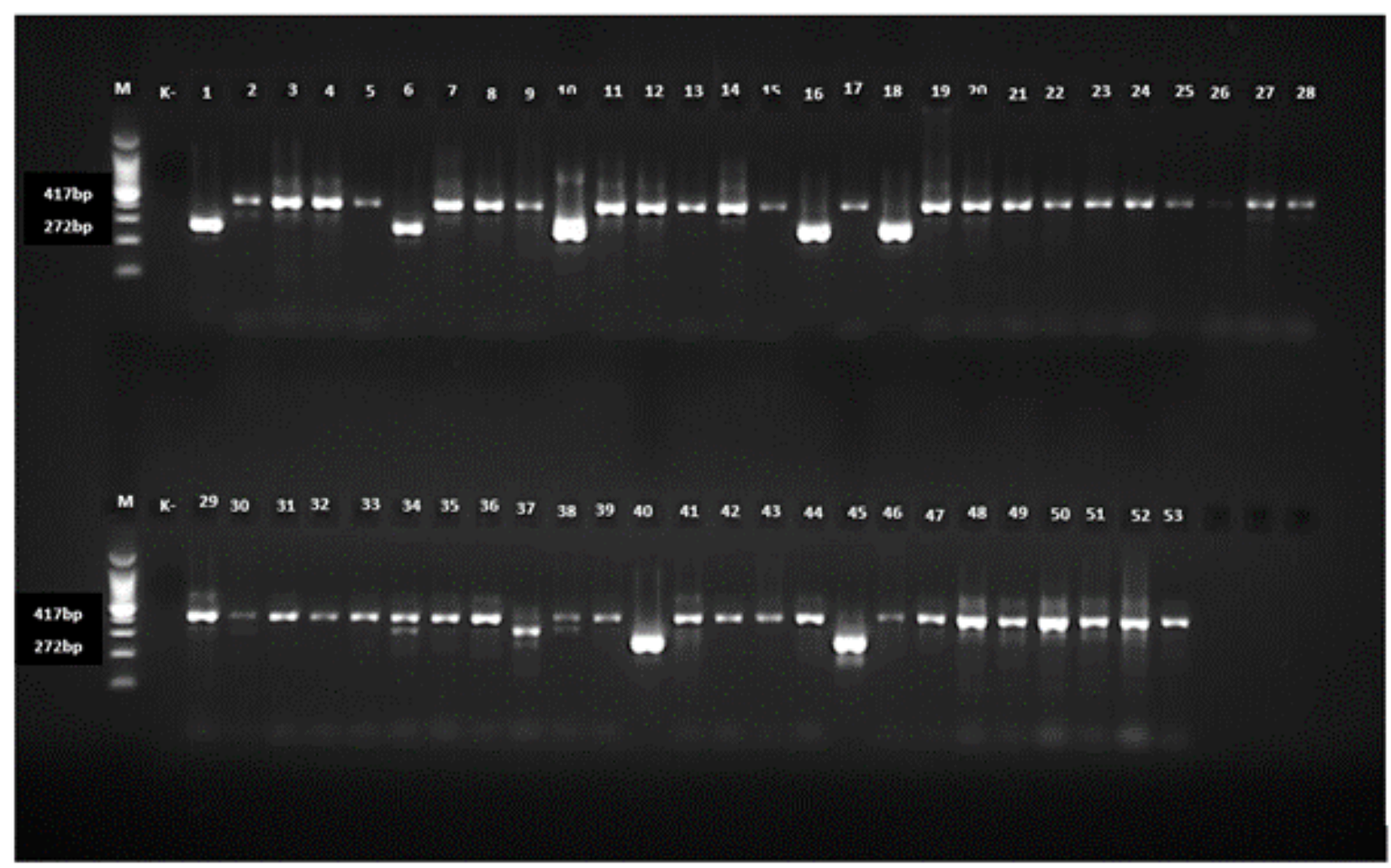

FIGURE 4 Electrophoresis reading result of nested PCR products of ITS2 Sarcoptes scabiei gene. M: 100 bp marker; K-: negative control; 1 - 53: positive-PCR samples (52 samples). 417 bp was a positive result of the first round of ITS2 gene. 272 bp was a positive result of the second round of the ITS2 gene. 
TABLE 3 Distribution of subjects based on key symptoms and dermoscopic examination $(n=52)$.

\begin{tabular}{lll}
\hline Parameter & Freq & $\%$ \\
\hline Nocturnal pruritus & & \\
Positive & 52 & 100 \\
Negative & 0 & 0 \\
\hline
\end{tabular}

\begin{tabular}{lll}
\hline Typical lesion and predilection & & \\
Typical lesion & 13 & 25 \\
Atypical lesion & 39 & 75 \\
Typical predilection & 48 & 92 \\
Atypical predilection & 4 & 8 \\
\hline
\end{tabular}

\begin{tabular}{lll}
\hline $\begin{array}{l}\text { Other scabies sufferers in the same } \\
\text { room }\end{array}$ & \\
Yes & 52 & 100 \\
No & 0 & 0 \\
\hline
\end{tabular}

Microscopic examination

\begin{tabular}{lll} 
Positive & 18 & 34.6 \\
Negative & 34 & 65.4 \\
\hline
\end{tabular}

TABLE 4 Diagnostic test of CO1 gene.

\begin{tabular}{llllll}
\hline & & \multicolumn{3}{c}{ Microscopic test result } \\
\cline { 2 - 4 } & & $(+)$ & $(-)$ & \\
\hline \multirow{2}{*}{ Nested PCR test result } & $(+)$ & 18 & 26 & 44 \\
& $(-)$ & 0 & 8 & 8 \\
& & 18 & 34 & 52
\end{tabular}

Sensitivity: 100\%; Specificity: 24\%; Positive predictive value: $41 \%$; Negative predictive value: $100 \%$; Accuracy: $50 \%$

ferers had never had this disease before. Scabies transmission mainly manifests clinically in patients who have never been exposed before because of lack of memory immunity, with reinfestation only occurring in $40 \%$ of patients because protective immunity has been developed (Hay et al. 2012).

The presence of two clinical symptoms out of the four cardinal signs is defined as a diagnostic cutoff. The nocturnal pruritus with the history of exact symptoms from other roommates was suffered up to $100 \%$. Sleep disruption is a common symptom of scabies, with nocturnal itching being the most noticeable, as mite activity peaks at night. Mite secretion and excretion products are specific antigens that mediate rapid hypersensitivity reactions consisting of skin inflammation, rashes and itching. Mites secrete proteases that activate protease-activated receptor 2 (PAR-2), an itch receptor. In addition, the immune response to mites also activates Th2, subsequently releasing several cytokines (including IL-31) that cause itchiness. Post-scabies itching can also occur due to immune response to antigen scabies and central nervous hypersensitivity (Jackson et al. 2007; Lavery et al. 2016; Ashok Nair et al. 2016).

Most subjects had few atypical lesions, confirming previous research that scabies generally presents with
TABLE 5 Diagnostic test of ITS2 gene.

\begin{tabular}{lllll}
\hline & & \multicolumn{3}{c}{ Microscopic test result } \\
& & $(+)$ & $(-)$ & Total \\
\hline \multirow{2}{*}{ Nested PCR test result } & $(+)$ & 18 & 34 & 52 \\
& $(-)$ & 0 & 0 & 0 \\
& & 18 & 34 & 52 \\
\hline
\end{tabular}

Sensitivity: 100\%; Specificity: 0\%; Positive predictive value: $34.62 \%$; Negative predictive value: -; Accuracy: $35 \%$

more than one type of lesion. Also, pathognomonic lesions, a form of tunnels with papules at the ends, are infrequent (Jackson et al. 2007). The topography of the scabies was mostly between the fingers, like a previous study (Hay et al. 2012). The dominant topography of this study was due to direct skin contact being more common via hands. In addition, this location has a thin and loose stratum corneum, making mite penetration easier (Walter et al. 2011).

The gold standard of scabies diagnosis is the microscope examination. The microscopic result of scabies infestation in our study is relatively high. Of the 52 skin scrapings samples, 18 (34.6\%) contained mites and eggs of S. scabiei. A study in 2011 reported 46\%, whereas another study in 2015 that only 17 out of 100 patients were microscopically positive (Walter et al. 2011; Wong et al. 2015). Commonly, atypical lesions in place of mites or eggs caused this low sensitivity, although dermoscopic examinations were performed before. Dermoscopic observations can provide false positives, especially in hyperpigmented skin, excoriated and crusted skin. Also, scratching by the subject can cause mechanical removal of the mite; thus, the microscopic examination yields a false negative. Most subjects had superinfection that decreased sensitivity because pus in the lesion is acaricide (Walter et al. 2011).

The microscope method has a lower sensitivity, moreover depends on the capability to scrape the skin and identify the mites, than a more sensitive test which is the biomolecular examination using PCR. Nested PCR analysis of the skin scraping samples that had already been examined microscopically revealed that 18 microscopic positive skin scrapings were positive (100\%) and 26 of 34 microscopic negative samples were positive $(76.47 \%)$ for the CO1. A higher number than a previous study, which was $14.4 \%$ and $25.7 \%$ using the same gene (Walter et al. 2011; Hahm et al. 2018). The sensitivity of nested PCR for $\mathrm{CO} 1$ genes to microscopic examination was $100 \%$. The same sensitivity was also found in previous studies at $100 \%$, which detected 28 positive-PCR samples but only detected nine from 25 microscopic negative samples (Hahm et al. 2018). Regarding the ITS2 gene nested PCR, all samples (100\%), both positive and negative microscopic skin scrapings, were analyzed. Previous studies were only able to identify 29 out of 53 positive microscopic samples (Fukuyama et al. 2010). PCR as a screening tool could be valuable for scabies, as a community densely populated disease and communicable disease out- 
break between passengers ship as reported by the Maritim Declaration of Health (MDH) (Hadjichristodoulou et al. 2011). This shows that the identification of nested PCR CO1 and ITS2 genes produced $100 \%$ sensitivity to the gold standard microscope examination.

The weakness of this current study is the low specificity of the PCR method for the diagnosis of scabies. The low specificity of PCR suggests for environment surveillance from desquamated skin, dust, or fomites samples that could contain living mite or egg (Hay et al. 2012; Wong et al. 2015). A negative microscopic sample still positive on the PCR method produced a false negative because PCR still detects DNA part of scabies even though mite has died (Fukuyama et al. 2010; Hay et al. 2012). PCR can also be considered an additional analysis in cases where clinical, dermoscopic or microscopic examination is negative, for example, in atypical and hidden scabies (Bezold et al. 2001).

We suggest further research on the immunodiagnostic of ordinary scabies, such as enzyme-linked immunosorbent assay (ELISA) to detect scabies-specific antibodies. In humans, this seems not feasible because of low var. hominis mite burden as antigen source and inability to take whole mite antigen (WMA) extract from in vitro culture. More than animals, recent-study already use ELISA with WMA extract to detect mange and are commercially available for canis infestation. Some animal studies develop recombinant immunogenic proteins such as Sar S 14.3, cofilin, and protein tyrosine kinase with up to $100 \%$ sensitivity and specificity scabies (Rampton et al. 2013). Whole-genome sequences of this potential diagnostic protein antigen are helpful to assess proteomic and genomic differences since scabies is known as the host-specific agent. Its analysis also could minimize cross-reactivity with house dust mites (Dean Rider et al. 2015). Some optimizations are worth considering the diagnostic tool of ordinary human scabies in the future.

\section{Conclusions}

In conclusion, dermoscopy oriented-nested PCR of CO1 and ITS2 could successfully identify S. scabiei infestations, with ITS2 being more sensitive than CO1, so that it could be considered a potential molecular identification tool and screening marker of ordinary scabies. The sequence analysis identified several species variations in these genes (accession numbers KJ748523 and AB778919).

\section{Acknowledgments}

This study was supported by a grant from the Faculty of Medicine, Sriwijaya University, Indonesia.

\section{Authors' contributions}

GDP designed the study. GDP, M, DH, AG, IAA, NDR carried out the laboratory work. GDP, DH, AG, AB analyzed the data. GDP, CA, DH, D, AG, AB wrote the manuscript. All authors read and approved the final version of the manuscript.

\section{Competing interests}

The author declare that they have no competing interest.

\section{References}

Arlian LG, Morgan MS. 2017. A review of Sarcoptes scabiei: Past, present and future. Parasites and Vectors 10(1). doi:10.1186/s13071-017-2234-1.

Ashok Nair PA, Vora RV, Jivani NB, Gandhi SS. 2016. A study of clinical profile and quality of life in patients with scabies at a rural tertiary care centre. J. Clin. Diagnostic Res. 10(10):WC01-WC05. doi:10.7860/JCDR/2016/20938.8703.

Bezold G, Lange M, Schiener R, Palmedo G, Sander C, Kerscher M, Peter R. 2001. Hidden scabies: diagnosis by polymerase chain reaction. $\mathrm{Br}$ J Dermatol. 144(3):614-618. doi:10.1046/j.13652133.2001.04096.x.

Dean Rider S, Morgan MS, Arlian LG. 2015. Draft genome of the scabies mite. Parasites and Vectors 8(1). doi:10.1186/s13071-015-1198-2.

Fukuyama S, Nishimura T, Yotsumoto H, Gushi A, Tsuji M, Kanekura T, Matsuyama T. 2010. Diagnostic usefulness of a nested polymerase chain reaction assay for detecting Sarcoptes scabiei DNA in skin scrapings from clinically suspected scabies. $\mathrm{Br}$ J Dermatol. 163(4):892-894. doi:10.1111/j.13652133.2010.09913.x.

Hadjichristodoulou C, Mouchtouri VA, Martinez CV, Nichols G, Riemer T, Rabinina J, Swan C, Pirnat N, Sokolova O, Kostara E, et al. 2011. Surveillance and control of communicable diseases related to passenger ships in Europe. Int Marit Health 62(2):138-147.

Hahm J, Kim C, Kim S. 2018. The efficacy of a nested polymerase chain reaction in detecting the cytochrome c oxidase subunit 1 gene of Sarcoptes scabiei var. hominis for diagnosing scabies. Br J Dermatol. 179(4):889-895. doi:10.1111/bjd.16657.

Hay R, Steer A, Engelman D, Walton S. 2012. Scabies in the developing world--its prevalence, complications, and management. Clin Microbiol Infect. 18(4):313323. doi:10.1111/j.1469-0691.2012.03798.x.

Hong MY, Lee CC, Chuang MC, Chao SC, Tsai MC, Chi CH. 2010. Factors Related to Missed Diagnosis of Incidental Scabies Infestations in Patients Admitted Through the Emergency Department to Inpatient Services. Acad Emerg Med. 17(9):958-964. doi:10.1111/j.1553-2712.2010.00811.x. 
Jackson A, Heukelbach J, da Silva Filho AF, de Barros Campelo Júnior E, Feldmeier H. 2007. Clinical features and associated morbidity of scabies in a rural community in Alagoas, Brazil. Trop. Med. Int. Health 12(4):493-502. doi:10.1111/j.13653156.2006.01809.x.

Karimkhani C, Colombara DV, Drucker AM, Norton SA, Hay R, Engelman D, Steer A, Whitfeld M, Naghavi M, Dellavalle RP. 2017a. The global burden of scabies: a cross-sectional analysis from the Global Burden of Disease Study 2015. Lancet Infect. Dis. 17(12):1247-1254. doi:10.1016/S14733099(17)30483-8.

Karimkhani C, Dellavalle RP, Coffeng LE, Flohr C, Hay RJ, Langan SM, Nsoesie EO, Ferrari AJ, Erskine HE, Silverberg JI, Vos T, Naghavi M. 2017b. Global skin disease morbidity and mortality an update from the global burden of disease study 2013. JAMA Dermatology 153(5):406-412. doi:10.1001/jamadermatol.2016.5538.

Kearse M, Moir R, Wilson A, Stones-Havas S, Cheung M, Sturrock S, Buxton S, Cooper A, Markowitz S, Duran C, Thierer T, Ashton B, Meintjes P, Drummond A. 2012. Geneious Basic: An integrated and extendable desktop software platform for the organization and analysis of sequence data. Bioinformatics 28(12):1647-1649. doi:10.1093/bioinformatics/bts199.

Lavery M, Stull C, Kinney M, Yosipovitch G. 2016. Nocturnal Pruritus: The Battle for a Peaceful Night's Sleep. Int J Mol Sci. 17(3):425. doi:10.3390/ijms17030425.

Liu JM, Chiu FH, Lin CY, Chang FW, Hsu RJ. 2017a. Incidence of autoimmune diseases in patients with scabies: a nationwide population-based study in Taiwan. Rheumatol. Int. 37(7):1125-1134. doi:10.1007/s00296-017-3717-2.

Liu JM, Hsu RJ, Chang FW, Yeh CL, Huang CF, Chang ST, Chiu NC, Chang HY, Chi H, Lin CY. 2017 b. Increase the risk of intellectual disability in children with scabies. Med. (United States) 96(23). doi:10.1097/MD.0000000000007108.

Liu JM, Wang HW, Chang FW, Liu YP, Chiu FH, Lin YC, Cheng KC, Hsu RJ. 2016. The effects of climate factors on scabies. A 14-year population-based study in Taiwan. Parasite 23. doi:10.1051/parasite/2016065.

Meyer EP, Heranney D, Foeglé J, Chamouard V, Hernandez C, Mechkour S, Passemard R, Berthel M, Kaltenbach G, Lipsker D, Christmann D, Lavigne T. 2011. Gestion d'une épidémie de gale aux Hôpitaux universitaires de Strasbourg. Med Mal Infect. 41(2):92-96. doi:10.1016/j.medmal.2010.07.011.

Mofiz E, Seemann T, Bahlo M, Holt D, Currie BJ, Fischer K, Papenfuss AT. 2016. Mitochondrial Genome Sequence of the Scabies Mite Provides Insight into the Genetic Diversity of Individual Scabies Infections. PLoS Negl. Trop. Dis. 10(2). doi:10.1371/journal.pntd.0004384.
Park JH, Kim CW, Kim SS. 2012. The Diagnostic Accuracy of Dermoscopy for Scabies. Ann Dermatol. 24(2):194. doi:10.5021/ad.2012.24.2.194.

Rampton M, Walton SF, Holt DC, Pasay C, Kelly A, Currie BJ, McCarthy JS, Mounsey KE. 2013. Antibody Responses to Sarcoptes scabiei Apolipoprotein in a Porcine Model: Relevance to Immunodiagnosis of Recent Infection. PLoS One. 8(6):e65354. doi:10.1371/journal.pone.0065354.

Sule HM, Dankyau M. 2015. Characteristics of Scabietic Lesions as Predictors of Microscopy Outcome in the Diagnosis of Scabies. Open Science J Clin Med. 3(6):224-229.

Walter B, Heukelbach J, Fengler G, Worth C, Hengge U, Feldmeier H. 2011. Comparison of Dermoscopy, Skin Scraping, and the Adhesive Tape Test for the Diagnosis of Scabies in a ResourcePoor Setting. Arch Dermatol. 147(4):468. doi:10.1001/archdermatol.2011.51.

Wong SSY, Poon RWS, Chau S, Wong SCY, To KKW, Cheng VCC, Fung KSC, Yuen KY. 2015. Development of Conventional and Real-Time Quantitative PCR Assays for Diagnosis and Monitoring of Scabies. J Clin Microbiol. 53(7):2095-2102. doi:10.1128/jcm.00073-15.

Zayyid MM, Saadah RS, Adil A, Rohela M, Jamaiah I. 2010. Prevalence of scabies and head lice among children in a welfare home in Pulau Pinang, Malaysia. Trop Biomed. 27(3):442-446. 